\title{
Magnitude estimation of the utility of nonmonetary items
}

\author{
SIMON KEMP \\ University of Canterbury, Christchurch, New Zealand
}

(K. T. Strongman, Sponsor)

\begin{abstract}
Magnitude estimation of the utility of personally and nationally consumed goods and services was undertaken by student and general public samples. For the personally consumed items, a power function with an exponent around 0.4 provided a good description of the relation between the utility of the items and their cost. Moreover, equivalent costs for uncosted personal items, such as fine weather on the following weekend, could be reliably obtained from the function. The utility of the national items, however, was virtually independent of cost.
\end{abstract}

It has long been known that the money value of a good or service is not the same as its subjective value to a potential consumer. There is a considerable literature on the measurement of utility, the term normally used to denote subjective value (e.g., Adams \& Fagot, 1959; Mosteller $\&$ Nogee, 1951; Wendt, 1982). The purpose of the present research was to investigate whether Stevens's power law and method of magnitude estimation (e.g., Stevens, 1957, 1975) can contribute to the measurement of utility.

Although attempts to describe the relationship of utility to monetary value by a power function have been infrequent, the first of these was apparently made by Gabriel Cramer in 1728, who proposed a power function with an exponent of 0.5 (Stevens, 1975). More recently, Galanter (1962) used a variant of magnitude estimation, asking subjects "How much [money would you want] in order to feel twice as happy as $\$ 10.00$ would make you feel?" (p. 211). His results were described by a power function with an exponent of 0.43 . Further experiments, using crossmodality matching and an English sample, yielded similarly sized exponents of 0.45 and 0.44 , respectively (Galanter, 1974).

All of the research performed to date has required subjects to assess the utility of sums of money. The present study, on the other hand, involved the assessment of the utility of specific items. Clearly, such research has the important aim of seeking to generalize the earlier results to a broader and less artificial range of commodities. There were, however, two additional considerations, both motivated by the desire to investigate practical applications for a utility scale.

I gratefully acknowledge the work of Cathy Clifton, who carried out many of the interviews. I am also grateful for the helpful comments and suggestions made by Alan Singer, Ming Singer, and Barrie Stacey on an earlier draft of the paper. The research was partly supported by the New Zealand Department of Labour. Address correspondence to Simon Kemp, Department of Psychology, University of Canterbury, Christchurch, New Zealand.
First, although many items or commodities have both a subjective and a monetary value, there are also many items for which a monetary value can be obtained only with difficulty, if at all. What, for example, is the monetary value of having fine weather next weekend or of obtaining a good grade on a school paper? If Stevens's power law describes the relation between the dimensions of utility and cost, as for example it does the relation between seriousness of crimes and prison terms for those crimes (Sellin \& Wolfgang, 1964), equivalent costs can be obtained for the uncosted items once the parameters of the power law are determined. The power law itself has the form:

$$
\psi=k \Phi^{n},
$$

where $\psi$ represents the psychological dimension, utility in this case; $\Phi$ is the presumably related physical or more objectively measured dimension, such as cost; $n$ is an exponent; and $k$ is a constant.

Second, knowing the utility rather than the cost of most consumer items probably has little practical significance. This is not true, however, of national or governmental items, that is, policies that a government or other body affected by political rather than market forces might carry out. The possibility exists that the method of magnitude estimation might provide a quick and easy method to determine the relative utility of different policies as perceived by the general public.

\section{METHOD}

\section{Respondents and Procedures}

Two separate samples filled out questionnaires. The student sample consisted of 114 undergraduate students in the psychology department. The median age of the students was 19. Fifty-two of the student respondents were male. All members of this sample answered the questionnaire simultaneously before the beginning of a lecture. The general public sample was obtained by area sampling of the Christchurch urban area. Members completed the questionnaire at home. The sample contained 46 men and 96 women and had a median age of 32 years. A paid assis- 
tant delivered the questionnaires to the general public sample and oversaw their completion.

\section{The Questionnaire}

The questionnaire was prefaced by a page outlining the aim of the study and pointing out that value or usefulness was not necessarily to be equated with cost. The bulk of the questionnaire consisted of items whose utility the respondent was requested to assess. Each questionnaire contained a list of personal items and a list of national items. These two lists appeared on separate pages, and pagination was varied. Complete lists of the items used and their approximate cost at the time of the survey are given in Table 1 . Personal items were chosen on the expectation that they would be rated as having positive value by the bulk of the sample, an expectation that was tested in a brief pilot survey. Thus items such as cigarettes, on whose utility there are sharply divergent views, were excluded. Note that four of the listed personal items were essentially cash sums. National items were chosen on the basis that they were either policies being pursued by the New Zealand government or policies that had at one time or another been suggested. Costings for these policies were obtained from a variety of governmental sources. They are subject to up to $20 \%$ error: official estimates are rarely completely accurate. Note that three of the listed items, relating to increases in the Family Benefit, are essentially the same policy but involve the expenditure of different sums of money. Two orderings of each list were used and a different standard item employed for each ordering. For the personal lists, the standards used were "a new color television set," assigned 100 units of value, and "dinner for two at the Sign of the Takahe," assigned 10 units. For the national lists, the stan- dards used were "providing paid employment on government-supported work schemes for all unemployed people," assigned 100 units, and "doubling government expenditure on preschool education and child care," assigned 10 units. Note that each respondent used either the 100 or the 10-unit personal standard and either the 100 - or the 10-unit national standard with the appropriate lists.

Before reading and assessing the personal items, the respondent was asked to

Make an estimate of the desirability, value, or usefulness to you of each of the items. Assume they are free and you are not expected to pay for them personally. Estimate each desirability or value relative to the standard ... [the standard was defined] ... If you think an item is three times as valuable as that, assign it $\mathbf{3 0 0}$ units [or 30 units, depending on the standard], if a tenth as valuable assign it 10 units [or 1 unit], and so on. Feel free to use fractions or decimals if you like. There are no correct answers; consider the value to you personally.

The list of items followed these instructions, and respondents wrote their responses alongside each item.

Instructions for the national list of items were similar. Respondents were asked to estimate

the desirability, value, or usefulness to New Zealand as a whole of each of the items. When doing this please ignore the costs of carrying out each item completely; consider only the value or use that N.Z. society might receive from each item.

The standard and its use were explained as for the personal list.

Table 1

Personal and National Items Used in the Questionnaire

\begin{tabular}{|c|c|c|}
\hline & Items & Cost $(\$ N Z)$ \\
\hline \multicolumn{3}{|c|}{ Personal } \\
\hline 1. & First prize in the Golden Kiwi $(\$ 100,000)$ & 100,000 \\
\hline 2. & An average Christchurch suburban house & 71,000 \\
\hline 3. & A new Toyota Corolla & 19,000 \\
\hline 4. & Being unexpectedly left a legacy of $\$ 5000$ by a distant relative & 5,000 \\
\hline 5. & Two weeks holiday for two in August in Fuji (accommodation, meals, airfare paid) & 4,300 \\
\hline 6. & A new color television set & 1,250 \\
\hline 7. & Winning a cash prize of $\$ 200$ in a sports club raffle & 200 \\
\hline 8. & A Shorter Oxford English Dictionary & 119 \\
\hline 9. & A year's subscription to The Press & 110 \\
\hline 10. & Dinner for two at the Sign of the Takahe & 65 \\
\hline 11. & One LP record of your choice & 13 \\
\hline 12. & A ticket to the cinema of your choice & 4 \\
\hline 13. & Picking up $\$ 2$ on a deserted street & 2 \\
\hline 14. & A can of fruit juice & 0.85 \\
\hline 15. & A pass with a grade of $A-$ in this paper (Student sample only) & \\
\hline 16. & Fine weather next weekend & \\
\hline
\end{tabular}

National

1. Increasing Family Benefit (currently $\$ 6 /$ child) by $\$ 20$ per week for each child

2. Providing paid employment on goverment-supported work schemes for all unemployed people

3. Increasing Family Benefit (currently $\$ 6 /$ child) by $\$ 10$ per week for each child

4. Increasing National Superannuation by $\$ 5 /$ week for each superannuitant

5. Increasing expenditure on the armed forces by $15 \%$ (Student sample only)

5a. Increasing expenditure on the armed forces by $10 \%$ (General public sample only)

6. Retaining all present passenger rail services

7. Removing all lead from New Zealand petrol

8. Increasing Family Benefit (currently $\$ 6 /$ child) by $\$ 1$ per week for each child

9. Doubling government expenditure on preschool education and child care

10. Providing another $\mathbf{1 0 0}$ police nationally

11. Funding a "stop smoking" campaign using $1 \%$ of the present tax on tobacco

12. Maintaining a nuclear-free New Zealand policy

13. Halting logging of native forest on the West Coast

Note-Average, actual, or estimated costs (in \$NZ) are shown for each item. Two items in each list have no estimated costs. Item 15 in the personal list was presented only to the student sample; Item 5 in the national list had slightly different versions for the two samples. Note that Items $1,4,7$, and 13 in the personal list are essentially cash items of different amounts; Items 1, 3, and 8 in the national list refer to the same basic policy but differ in the amounts to be spent. 
Of the student sample, 51 respondents responded to the personal list with the standard of 10 units, and 63 employed the 100-unit standard. For the national list, 52 responded to the 10-unit standard, and 61 to the 100-unit standard. Of the general public, 57 responded to the personal list with the 10-unit standard, and 85 used the 100-unit standard. Seventy-one responded to each standard with the national list.

\section{RESULTS}

Results relating to the personal items are presented in Figure 1, where the median estimated utility is plotted as a function of actual cost for those items for which an actual cost was available. Inspection of the figure shows that the results from the two samples and the two standards are generally very similar. The calculated power-law exponents are all in the range $0.33-0.46$. Correlations between the estimates and the costs are 0.94 or 0.95 . Interquartile deviations are roughly similar in the four quarters of Figure 1.

The consistency of results obtained with the two standards indicates that respondents in both samples generally used the method of magnitude estimation successfully. That the data generally lie close to the fitted line indicates that the power law is a good description of the relationship between the estimates and the actual costs. This conclusion is strengthened by the correlations obtained, which compare favorably to those from other studies in which some sort of social consensus has been measured. For example, Sellin and Wolfgang (1964) found correlations between estimated seriousness of offenses and maximum prison terms for those offenses of 0.88 for a student sample and 0.94 for a police sample. Rather higher correlations, of the order of 0.99 , are often obtained between magnitude estimates and physical values in sensory dimensions, and occasionally in studies in scaling social variables (Hamblin, 1974);

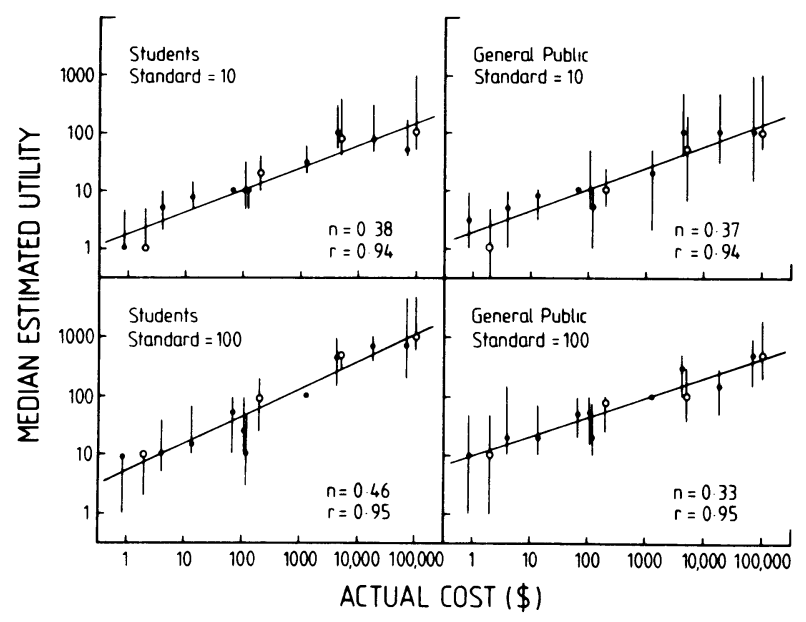

Figure 1. Median estimated utility as a function of actual cost for 14 costed personal items. The four cash item medians are shown by open circles, the other item medians by closed circles; the interquartile ranges are indicated by vertical lines. Actual item descriptions are shown in Table 1 in the same order (i.e., of cost) shown in the figure. Results obtained from the different samples and standards are shown in the separate quadrants of the figure. The least squares line of best fit, its slope ( $n$ ), and the correlation ( $r$ ) for each sample and standard are also shown. however, in such studies as, for example, the scaling of the loudness of sound, typically only one physical dimension (e.g., intensity) is varied while other physical parameters (e.g., frequency or spectral composition) are kept constant. In the present study, by contrast, respondents estimated the utility of items that differed not only in cost but in other ways as well. The addition of such extra variability should, on statistical grounds alone, lead to lower correlation, as was found.

Three of the four power-law exponents obtained from the present study are lower than the values of 0.43 to 0.45 found by Galanter $(1962,1974)$, although the difference is not great. Such slightly lower exponents might also have arisen from the greater variability introduced by asking respondents to estimate the utility of different items rather than of monetary sums. Exponents calculated from the four cash items in the present study were 0.34 for the general public, standard 10 sample, and 0.44 for each of the other three groups. The difference, however, between the sets of values is small and, as is clear from Figure 1, the cash items appear to be described by the same function as other items.

Table 2 shows the estimated utility for the uncosted personal items. Equivalent costs also were estimated for these items, obtained by inserting the median utility estimates into the power-law equation and "working backward" to derive a cost value. It is noteworthy that the estimated costs derived using the different standards are similar for both items and samples, and this result confirms that there generally was a close relationship between estimated utility and cost for the personal items. It is also interesting to note that the interquartile ranges reported for the uncosted items are similar to those shown in Figure 1 for the costed items. This result indicates that the estimation of utility is not greatly affected by whether a cost can be readily attached to a particular item.

Figure 2 shows the median estimated utility plotted against the actual annual cost for the national items. As is clear from the values of the exponents and the correlations, as well as from inspection of the figure itself, there is effectively no relationship between the estimated utility of the national items and their cost.

The lack of relationship does not appear to have arisen because of substantial individual or group differences or because of difficulties with the method. Although the interquartile ranges shown are often larger for the national items than for the personal items, preferences for particular policies are relatively stable across samples and standards. Thus the utility of increasing expenditures on the armed forces was uniformly assessed to be low while that of maintaining a nuclear-free New Zealand was assessed highly. Moreover, for both samples and standards, increasing the Family Benefit by $\$ 10$ per week was assessed as more useful than increasing it by $\$ 1$ or $\$ 20$.

\section{DISCUSSION}

Respondents in both samples of the present study produced consistent estimates of the utility of the personal items. Evidence for this consistency comes from the similarity of the results obtained with the two 
Table 2

Median Estimated Utility for the Uncosted Personal Items

\begin{tabular}{|c|c|c|c|}
\hline & \multicolumn{2}{|c|}{ Utility } & $\begin{array}{c}\text { Estimated Cost } \\
(\$ N Z)\end{array}$ \\
\hline \multicolumn{4}{|c|}{ Item 15. Pass with a grade of $\mathrm{A}-$. } \\
\hline Students: & $\begin{array}{l}\text { Standard }=10 \\
\text { Standard }=100\end{array}$ & $\begin{array}{c}50(20,100) \\
1300(100,1000)\end{array}$ & $\begin{array}{l}6,160 \\
6,060\end{array}$ \\
\hline \multicolumn{4}{|c|}{ Item 16. Fine weather next weekend. } \\
\hline $\begin{array}{l}\text { Students: } \\
\text { General Public: }\end{array}$ & $\begin{array}{l}\text { Standard }=10 \\
\text { Standard }=100 \\
\text { Standard }=10 \\
\text { Standard }=100\end{array}$ & $\begin{array}{l}10(3,30) \\
50(10,100) \\
20(5,100) \\
90(20,150)\end{array}$ & $\begin{array}{r}88 \\
122 \\
573 \\
427\end{array}$ \\
\hline
\end{tabular}

Note-Upper and lower quartile estimates are given in brackets. Also given is the "equivalent cost" derived from the estimated power function for that sample and standard.

standards and, in particular, from equivalent cost results reported in Table 2. It is also clear that the relationship between the utility of the personal items and their cost is described rather well by a power function with an exponent of about $0.40 \pm 0.05$. The range of values is in agreement with the previous results of Galanter $(1962,1974)$ and indicates that the utility of personal items of the kind estimated here is assessed in a similar way to the utility of sums of money.

The results obtained from the uncosted personal items not only provide a check on the consistency of the respondents' estimates using the two standards, but also suggest that the magnitude estimation of utility may have practical application. It appears that utility estimation is not substantially affected by whether a price can be readily attached to an item. Thus items can be placed on the same scale of utility, regardless of whether they can be readily costed. Such a scale can itself be used to measure utility, or, provided some items that can be costed are included, a power function can be derived and equivalent costs obtained. Thus, in practice, the utility of so-called intangibles can be measured and compared with that of more easily priced goods and services.

There is no necessary economic reason why utility and costs should be strongly related for personal or national items. Air, for example, is costless but clearly of great utility. However, it is difficult to see why,

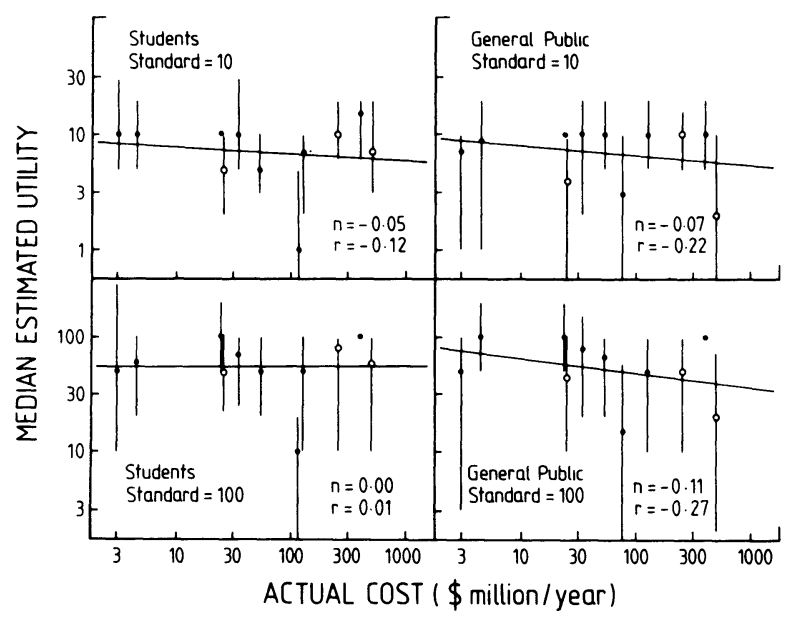

Figure 2. Median estimated utility as a function of estimated annual cost for 11 costed national items. The three items' medians relating to the Family Benefit are shown by open circles, the other items' median by closed circles; the interquartile ranges are indicated by vertical lines. Actual item descriptions are shown in Table 1 in the same order (i.e., of cost) shown in the figure. Results obtained from the different samples and standards are shown in the separate quadrants of the figure. The least squares line of best fit, its slope $(n)$, and the correlation $(r)$ for each sample and standard are also shown. in the present study, the power law should describe the relationship of utility to costs for personal items but not for national items. Indeed, for the latter, there seems to have been no relationship at all between the two variables. Broadly speaking, there seem to be two possible explanations as to why the results obtained with national items are so different from those obtained with the personal items. First, it is possible that, despite the consistencies obtained, respondents could not properly estimate the utility of the national items. Such inability might have occurred, for example, if they were unable to disregard the actual costs as instructed. In New Zealand, as in most other countries, citizens are frequently admonished by politicians and economists that desirable social services must eventually be paid for. Some indication in the present results that costs were not disregarded is provided by the fact that the $\$ 20$ increase in Family Benefit was consistently rated less desirable than the $\$ 10$ increase. This is possibly because the $\$ 20$ increase was perceived as too expensive. A further indication is provided by the overall result: if respondents took cost into account in assessing utility and actually estimated utility per dollar spent, then their utility estimates should be independent of cost, as was effectively found. The first explanation basically posits that the lack of relationship found between utility and cost was artifactual, but it is also possible, although I think less likely, that it was real; that is, it is conceivable that there is little relationship between utility and cost for national items and governmental decisions.

\section{REFERENCES}

Adams, E. W., FAGOT, R. (1959). A model of riskless choice. Behavioural Science, 4, 1-10.

Galanter, E. (1962). The direct measurement of utility and subjective probability. American Journal of Psychology, 75, 208-220.

Galanter, E. (1974). Psychological decision mechanisms and perception. In E. C. Carterette \& M. P. Friedman (Eds.), Handbook of perception: Vol. 2. Psychophysical judgment and measurement (pp. 85125). New York: Academic Press.

Hamblin, R. L. (1974). Social attitudes: Magnitude measurement and theory. In H. M. Blalock (Ed.), Measurement in the social sciences: Theories and strategies (pp. 61-120). London: Macmillan.

Mosteller, F., \& NoGee, P. (1951). An experimental measurement of utility. Journal of Political Economy, 59, 371-404.

Seluin, J. T., \& Wolfgang, M. E. (1964). The measurement of delinquency. New York: Wiley.

Stevens, S. S. (1957). On the psychophysical law. Psychological Review, 64, 153-181.

Stevens, S. S. (1975). Psychophysics: Introduction to its perceptual, neural, and social prospects. New York: Wiley.

WendT, D. (1982). On S. S. Stevens: Psychophysics and the measurement of subjective probability and utility. In B. Wegener (Ed.), Social attitudes and psychophysical measurement (pp. 303-314). Hillsdale, NJ: Erlbaum.

(Manuscript received March 23, 1988.) 